\title{
A Gestão dos Resíduos Sólidos de Serviço de Saúde na cidade de Criciúma/SC
}

\author{
Tatiane Gomes Nazário (UNESC) tatianenazario@hotmail.com \\ Ednilson Viana (UNESC) edv@unesc.net \\ Teresinha Maria Gonçalves (UNESC) tmg@unesc.net
}

\begin{abstract}
Resumo
Este estudo discute o cenário da gestão ambiental dos resíduos sólidos dos Serviços de Saúde da cidade de Criciúma - SC. A discussão parte da análise dos resultados da pesquisa realizada nos anos de 2004/2005 com o apoio da Universidade do Extremo Sul Catarinense/Unesc, coordenada e executada pelos autores. Foram amostrados 76 estabelecimentos distribuídos em consultórios, farmácias, clínica médicas, consultórios e clínicas odontológicas, clínicas de repouso, hospitais, unidades de saúde e clínicas veterinárias. Este artigo discute os dados colhidos nesses estabelecimentos exceto os hospitais e unidades de saúde. Os resultados da pesquisa mostraram que há um descompasso entre os órgãos normatizantes (ANVISA) e os órgãos executores, ou seja, os serviços de saúde. A maioria dos estabelecimentos desconhecem as normas da ANVISA e são apoiados por uma Vigilância Sanitária deficitária. Isto implica em um maior risco de contaminação do meio ambiente e de saúde da população. Na opinião da maioria dos entrevistados cabe ao poder público dar a solução para o destino final dos diferentes resíduos de saúde.

Palavras-chave: resíduos de serviço de saúde, gerenciamento, saúde pública
\end{abstract}

\section{Introdução}

A análise dos vários estabelecimentos prestadores de serviços de saúde é parte de um projeto maior de delineamento da gerência dos resíduos sólidos na cidade de Criciúma/SC, cujo título é: O CENÁRIO DA GESTÃO DOS RESÍDUOS SÓLIDOS DA CIDADE DE CRICIUUMA PARA A COLETA INFORMAL, RESÍDUOS DE SERVIÇO DE SAÚDE E RESÍDUOS DA CONSTRUÇÃO CIVIL.

Em nosso estudo nos propomos conhecer e analisar a realidade da gestão dos resíduos sólidos de serviço de saúde, o comumente chamado lixo hospitalar, na cidade de Criciúma/SC. Através dos dados obtidos, esperamos ser possível iniciar um processo de delineamento do cenário da gestão desses resíduos na cidade e favorecer a busca de métodos e técnicas que propiciem uma melhoria do processo de gestão e conseqüentemente da qualidade de vida da população.

Sabe-se que a gestão inadequada dos resíduos sólidos pode gerar sérias conseqüências tanto para o meio ambiente quanto para a saúde da população. Por outro lado, propor melhorias ou formular um plano de gestão para tais resíduos depende do conhecimento prévio da realidade de tratamento e disposição em que se encontram estes resíduos.

Até a década de 80, os resíduos considerados perigosos incluíam aqueles provenientes de hospitais. A denominação "lixo hospitalar" tornou-se comumente utilizada, mesmo quando os resíduos não eram gerados em unidades hospitalares. (LICENCIAMENTO..., 2004). Atualmente, esse termo foi substituído por resíduos sólidos de serviços de saúde, que engloba os resíduos produzidos por todos os tipos de estabelecimentos prestadores de serviços de 
saúde - hospitais, ambulatórios, consultórios médicos e odontológicos, laboratórios farmácias, clínicas veterinárias, entre outros. (LICENCIAMENTO..., 2004)

Segundo define a Resolução 283 do Conselho Nacional do Meio Ambiente - CONAMA - de 12 de julho de 2001, Resíduos Sólidos de Serviços de Saúde (RSSS) são aqueles provenientes de qualquer unidade que execute atividades de natureza médico-assistencial humana ou animal, os provenientes de centros de pesquisa, desenvolvimento ou experimentação na área de farmacologia e saúde, medicamentos e imunoterápicos vencidos ou deteriorados, aqueles provenientes de necrotérios, funerárias e serviços de medicina legal e aqueles provenientes de barreiras sanitárias.

Com efeito, a Resolução CONAMA No 5 de 05 de agosto de 1993 representou um marco nesse assunto, classificando os resíduos de serviços de saúde segundo o risco e atribuindo aos vários agentes envolvidos - geradores, autoridades sanitárias e ambiental - claras responsabilidades frente ao gerenciamento desses resíduos. (LICENCIAMENTO..., 2004). Por este motivo, o estabelecimento de um plano de gestão adequado de tais resíduos é de grande importância e segundo a Resolução é indispensável.

No Brasil, são geradas cerca de 120 mil toneladas de lixo urbano por dia. Um a três por cento desse total é produzido nos estabelecimentos de saúde e, destes, $25 \%$ a $10 \%$ representam risco ao meio ambiente e a saúde da população (ANVISA, 2004). Em termos quantitativos, eles representam uma pequena parcela do total de resíduos produzidos. Apesar disso, ocupam lugar de destaque pelo risco potencial como fonte de organismos patogênicos, pelo caráter infectante de alguns de seus componentes ou pela heterogeneidade de sua composição (substâncias tóxicas, radioativas, cortantes, etc.) (COSTA, 2001; SCHNEIDER et al, 2001), sem contar a deterioração estética da paisagem natural e dos centro urbanos. Neste aspecto, o gerenciamento dos RSSS é tido como o instrumento capaz de minimizar ou até impedir os efeitos adversos do ponto de vista sanitário, ambiental e ocupacional, em cada fase do processo (RISSO, 1993).

A normalização sobre Resíduos de Serviço de Saúde é extensa e tem como órgãos normalizadores a ANVISA (Agência Nacional de Vigilância Sanitária) e o CONAMA (Conselho Nacional do Meio-Ambiente). As resoluções CONAMA e as RDCs da ANVISA são o principal material disponível sobre gerenciamento desses tipos de resíduos, considerados perigosos e sob as quais nos pautamos para realizar a pesquisa de campo.

A RDC 33 de 25 de fevereiro de 2003, referente ao Gerenciamento dos Resíduos de Serviço de Saúde, deu o passo inicial sobre o gerenciamento desses resíduos e causou muitas discussões. Em alguns de seus pontos ela entrava em conflito com Resoluções CONAMA e teve que ser modificada, dando origem a atual RDC 306 de 07 de dezembro de 2004, revogando a norma anterior e dando o prazo a partir de sua publicação para os estabelecimentos se adequarem a essa nova legislação.

\section{Descrição da Metodologia}

Buscou-se inicialmente, junto a Secretaria Municipal de Saúde, na Assessoria de Imprensa da prefeitura e na Vigilância Sanitária o cadastro de todos os estabelecimentos de Saúde existentes em Criciúma. Com a relação dos estabelecimentos cadastrados, pode-se delimitar a amostra de pesquisa, segundo Stevenson (1986), para 76 estabelecimentos, dos 368.existentes na cidade. A amostra foi definida considerando população finita e proporcional ao número de estabelecimentos por estrato.

Com a definição da amostra, elaborou-se um questionário a partir da resolução RDC 33 de 25 de fevereiro de 2003. Embora não seja a mesma lei tomada como base para a análise dos resultados, os pontos principais relacionados ao gerenciamento não incorreram em grandes 
mudanças para a pesquisa quando da revogação desta para o lançamento da RDC 306 de 07 de dezembro de 2004. Com o questionário pronto no mês de julho de 2004, pôde-se elaborar um plano de saída de campo, efetuado a partir do mês de agosto do mesmo ano. Foram visitados 62 estabelecimentos. Os estabelecimentos visitados foram farmácias, consultórios e clínicas médicas, consultórios e clínicas odontológicas, clínica fisioterápica, casa de repouso e clínica veterinária. Os dados encontrados a partir dessas visitas foram organizados em tabelas e tratados estaticamente.

\section{Análise dos dados}

Em relação à saúde em Criciúma, foi solicitado dos entrevistados, a visão deles sobre tal aspecto. O resultado foi que $26 \%$ deles percebem a saúde de Criciúma como ruim e que deveria ser melhorada em diversos pontos. Contudo não sabiam apontar os pontos onde essas colocações se faziam adequadas.

Uma grande maioria dos entrevistados (67\%) afirmam que o lixo produzido nos estabelecimentos representa perigo para a população. Sobre esse assunto, os entrevistados souberam falar com precisão sobre o risco potencial desses tipos de resíduos, porém, a única associação feita nesse aspecto, era relacionada à contaminação biológica. Nenhum dos entrevistados exploraram mais essa questão, falando da forma como essa contaminação se processa.

Em se tratando da responsabilidade quanto ao destino final dos resíduos, $62 \%$ dos entrevistados atribuem a responsabilidade do lixo produzido, ao menos em sua destinação final, a prefeitura. Por volta de $21 \%$ dos entrevistados ainda conferem a responsabilidade à Vigilância Sanitária. A norma RDC 306 de 7 de dezembro de 2004, (ANVISA, 2004) diz que:

os serviços de saúde são os responsáveis pelo correto gerenciamento de todos os RSSS por eles gerados, atendendo às normas e exigências legais, desde o momento de sua geração até a sua destinação final; considerando que a segregação dos RSSS, no momento e local de sua geração.

Deste modo, é incorreto pensar ser apenas responsabilidade de um órgão público o descarte do lixo produzido pelo próprio estabelecimento. Esse cuidado é uma obrigação principalmente do gerador. Contudo, os órgãos públicos deveriam estar empenhados em solucionar o problema do descarte, pois um estabelecimento de saúde não poderia criar seu próprio aterro sanitário.

Mesmo assim existe uma falta de consciência dentre os estabelecimentos prestadores de serviço de saúde e 58\% dos entrevistados relatam não saberem a destinação final dos resíduos depois de saírem dos estabelecimentos Deste modo, não se pode esperar uma visão mais ampla sobre o gerenciamento dos resíduos, pois os entrevistados, mal conseguem identificar a existência de incinerador na Cidade, apesar de $17 \%$ dos entrevistados afirmarem ser este o destino final dos Resíduos de Serviço de Saúde em Criciúma. Por outro lado, $25 \%$ dos entrevistados afirmam existir um aterro sanitário, com todas as especificações necessárias para poder realizar esse trabalho de descarte final.

Por aterro sanitário entende-se uma

técnica de disposição final de resíduos sólidos urbanos no solo, por meio de confinamento em camadas cobertas com material inerte, segundo normas 
específicas, de modo a evitar danos ou riscos à saúde e à segurança, minimizando os impactos ambientais. (ANVISA, RDC 306, 2004)

O aterro existente em Criciúma, situado próximo a Unesc, está longe de ter as características acima descritas, pois cavar um buraco na terra, jogar o lixo e depois tapá-lo não pode ser considerado um aterro sanitário. Tem-se na região, um aterro controlado, mas não comporta formas adequadas de disposição desses resíduos, portanto, nossa afirmação acima, ainda é verdadeira.

Um adequado sistema de armazenamento, acondicionamento, transporte e destino final dos resíduos deve seguir um plano de gerenciamento em suas mais peculiares etapas. Por não saberem qual o caminho percorrido pelo lixo desde sua geração até seu descarte final, quando os entrevistados discorrem sobre as formas adequadas dos itens relacionados acima, eles se apegam em um dos fatores, não sendo capazes de avaliar todas as etapas por onde o lixo transita. Dos entrevistados, 49,2\% afirmam ser adequado à seleção o uso de luvas, armazenamento na forma correta, identificação dos resíduos e retirada diária. Por essas respostas, faz-se algumas pontuações importantes. Embora superficiais, algumas pessoas afirmam a importância da seleção, outras do armazenamento adequado, mas poucas foram aquelas a relacionar mais de um fator sobre o caminho adequado dos resíduos desde a geração até o destino final.

Deste modo, ainda é importante pontuar que $14,3 \%$ dos entrevistados consideram-se inaptos para falar a respeito de como proceder com relação ao lixo. Afirmam necessitarem de maior instrução a fim de terem alguma noção sobre os tipos de resíduos que manuseiam diariamente e suas implicações. Para $20,6 \%$ dos entrevistados, a incineração é tida como a forma mais adequada de destinação final. Por outro lado, eles não focam o modo como ele é tratado até o momento do descarte e julgam que o destino final é um problema, como alguns verbalizaram em suas respostas. Mesmo estes não citaram nenhuma ação para uma melhoria do gerenciamento interno dos resíduos.

É interessante observar, na resolução RDC 33 de 25 de fevereiro de 2003, a desobrigação do uso de incineradores nos estabelecimentos de saúde. Foi exatamente em relação a essa desobrigação, severamente criticada. A incineração é um método de disposição final gerador de alguns tipos de compostos e poluentes. Contudo, para lugares onde não existe uma disposição final adequada essa desobrigação torna-se extremamente perigoso.

Segundo Rodriguez (apud LIXO, 2004),

\begin{abstract}
$88 \%$ dos aterros sanitários do país são inadequados. Além de catadores de lixo, os aterros não têm impermeabilização do solo e sistema de captação e tratamento do chorume, com riscos de contaminação do lençol freático. Dos resíduos de serviço de saúde coletados diariamente no país, cerca de 800 toneladas necessitam de tratamento especial.
\end{abstract}

De acordo com os números do IBGE 2000 apud LIXO (2004) 5.475 municípios brasileiros com serviços de limpeza urbana, 63,3\% (3.466 municípios) coletam resíduos de serviço de saúde. A grande maioria (2.569) desses municípios destina os resíduos coletados para o mesmo local do resto do lixo (vazadouro ou aterro). Apenas $15 \%$ utilizam aterros de resíduos especiais.

Mesmo com um sistema de gerenciamento inadequado, órgãos como a Prefeitura e a Vigilância Sanitária da cidade de Criciúma parecem estar pouco comprometidos com essa 
questão do lixo. Isto porque aproximadamente $48 \%$ dos entrevistados afirmaram não receber qualquer visita, seja da prefeitura ou de outro órgão para orientação. Em 32\% dos casos afirmam receber a Vigilância Sanitária e orientação. Para 11\% a Vigilância apenas fiscaliza e não oferece orientações. Esse fator é de suma importância, pois o compromisso desses órgãos também é o de disponibilizar informações sobre questões de saúde pública.

Não somente os profissionais não conhecem a ANVISA, como também não tiveram qualquer contato com a normalização elaborada para os resíduos de serviço de saúde. Os $78 \%$ dos entrevistados disseram não conhecer as normas muitos, inclusive, afirmam que ela é um órgão criado apenas para fins de arrecadação financeira. Dos $22 \%$ que dizem conhecer as normas, na verdade não as conhecem por completo, conhecendo apenas as questões relacionadas ao seu próprio estabelecimento, ou ainda dizem ser conhecer, no sentido de já terem ouvido falar a respeito. Preocupante foi o fato de alguns profissionais relatarem não saberem da existência da Agencia Nacional de Vigilância Sanitária.

Os resíduos, na sua grande maioria dos estabelecimentos entrevistados (93\%), não possuíam qualquer forma especificada de manejo, mesmo rudimentar. Notou-se, por meio de observação, que muitos dos entrevistados não viam necessidade na visita do pesquisador ao local de geração de resíduos e faziam questão de relatar o que ocorria com o lixo em seu estabelecimento, apenas dizendo que eram separados, colocados em plástico branco e/ou descartex para perfurocortantes e que existia uma empresa diferenciada fazendo o serviço de recolhimento. Era tudo o que poderiam relatar sobre o lixo, comentando ser infundada uma visita, pois uma pesquisa referente ao lixo não teria grandes enfoques e deveria se resumir a essas questões.

De acordo com a RDC 306 de 07 de dezembro de 2004 (ANVISA, 2004), os geradores de RSS devem adotar um Programa de Gerenciamento de Resíduos de Serviço de Saúde. Esse programa constitui-se num conjunto de procedimentos de gestão, planejados e implementados a partir de bases científicas, normativas e legais com o objetivo de minimizar a produção de resíduos e proporcionar aos resíduos gerados um encaminhamento seguro, de forma eficiente, visando à proteção dos funcionários, à preservação da saúde pública, dos recursos naturais e do meio ambiente (CAMPANER \& SOUZA, 2004).

Sem conhecer as normas não é possível existir um plano de gestão de resíduos. Talvez pudéssemos atribuir a inexistência de um plano às diversas mudanças ocorridas na legislação em um período curto de tempo e compreenderíamos uma inadequação dos estabelecimentos, confusos com tantas mudanças. Contudo, não é esse o caso, pois $98 \%$ dos entrevistados não possuíam o plano de gestão, obrigatório desde o momento da publicação das normas RDCs. $\mathrm{O}$ motivo é simples, eles sequer sabiam da existência das normas, nem imaginavam ser necessário um planejamento para algo "tão simples" como o descarte de lixo. Qualquer orientação referente aos resíduos de serviço de saúde são repassadas oralmente, pelos superiores, pela empresa que recolhe os resíduos ou pela fiscalização da Vigilância Sanitária. Inclusive, esta, em determinados estabelecimentos, leva mais de um ano até realizar uma visita.

Quanto à produção semanal de lixo nos estabelecimentos pesquisados, $80 \%$ dos entrevistados produzem semanalmente de 100 a $700 \mathrm{~L}$ de lixo e $14 \%$ dos entrevistados produzem semanalmente menos de $100 \mathrm{~L}$ de lixo. Com relação à quantidade de resíduos perigosos produzidos $45 \%$ dos entrevistados relataram produzir de 2 a $15 \mathrm{~L}, 26 \%$ acima de $300 \mathrm{~L}$ e $21 \%$ de 101 a 300L. A primeira vista parece uma quantidade irrisória de resíduos produzidos, mas considerando a abrangência desses estabelecimentos esta se torna uma quantidade considerável. Isso é preocupante a medida em que os estabelecimentos se descuidam destes resíduos por serem em pequena quantidade e se presume, por conta disso, poucos riscos. Esse pensamento até poderia ter uma lógica, contudo, os valores relatados nessa questão nem sempre eram relacionados à produção semanal, mas de várias semanas, de dois, de três, de 
seis meses a até de um ano. Isto porque o lixo ficava todo esse tempo a espera da coleta, até que se conseguisse atingir determinada quantidade para ser descartado finalmente. Apenas uma seringa descartada pode ter um potencial infectante muito grande se deixada por um longo período de tempo exposta da forma como ocorre com esses materiais em determinados lugares, normalmente farmácias.

Se a lei existe para ser cumprida, porque não se tem condições de cumpri-la? Porque não se é amparado para se poder tomar as devidas providencias? Há que se destacar que culturalmente não se tem responsabilidade pelo lixo que se produz. Isto remete a uma questão maior, pois se a própria população acreditasse que o lixo é uma questão importante, esse problema já estaria entre as promessas eleitorais. Da mesma forma que ocorre com o tratamento de esgoto, inexistente em Criciúma, onde o poder público não pensa em "dar jeito" em algo que não vai trazer votos, que "não aparece". Por isso o problema vem se arrastando e a implantação da normalização torna-se algo realmente difícil de ser concretizado.

Em 38\% dos estabelecimentos, o órgão responsável pela coleta final dos resíduos é a prefeitura e $21 \%$ afirmam ser uma empresa terceirizada e $21 \%$ não sabem ou não responderam. Contudo, é unânime a falta de contato com o profissional da coleta. Em alguns lugares o contato ocorre quando da entrega do lixo em mãos pelo profissional. Em outros casos os funcionários do estabelecimento de saúde apenas fazem a seleção e deixam num local previamente especificado onde o profissional passa, recolhe o lixo e freqüentemente mal é visto entrando no estabelecimento. Essa prática é constante e traz preocupações, pois se o estabelecimento é responsável pelo lixo produzido neste, não somente o contato como a verificação de como essa coleta está sendo realizada é de extrema importância. É uma questão de responsabilidade para com o produto final do trabalho.

Em relação à sala para guarda temporária dos resíduos internamente no estabelecimento, nenhum dos estabelecimentos visitados possuía uma sala para armazenamento temporário dos resíduos. Existe uma consideração na norma que justifica a não existência dessa sala quanto a distância entre o ponto de geração e o armazenamento externo sejam ínfimas. (RDC 306, 1.5.1, capítulo III). Contudo, não existe referência a tamanhos, indicando a partir de quantos metros quadrados deveria se adotar o uso da sala para armazenamento temporário de resíduos.

A grande maioria dos estabelecimentos visitados, ou seja, 31\% não possuem abrigos para armazenamento externo dos resíduos. Talvez, este seja ainda mais essencial do que o próprio abrigo interno, pois tira de circulação no estabelecimento o lixo depois de sua geração. Somente essa medida poderia evitar uma série de possíveis "problemas" relacionados com o lixo. Ainda $25 \%$ dos estabelecimentos possuem um local coletivo para os diversos estabelecimentos de saúde existentes no prédio, onde o lixo é armazenado. Poucos puderam responder como exatamente é esse local e nenhum deles nunca entrou em contato com o lugar de armazenagem, sendo que apenas sabem de sua existência. O pensamento que impera é aquele de que o cuidado se encontra até a porta do "meu estabelecimento", fora dali, já "não cabe mais a mim" responder pelos resíduos. Seu destino final ficará por conta de outros órgãos.

Por destinação final entende-se o confinamento dos resíduos em aterros sanitários especificamente projetados, observando as características geológicas, hidrogeológicas, tratamento de efluentes e o monitoramento permanente da área. Para os RSSS, por determinação da Resolução CONAMA 05/93, não é permitida a co-disposição com resíduos domiciliares e nem a disposição dos resíduos sem tratamento prévio; as áreas destinadas a aterro de RSSS devem ser licenciadas e operadas exclusivamente para este fim. (A SITUAÇÃO..., 2004) 
Além da questão da destinação final dos RSSS, adiciona-se a esse fator a questão cultural da população envolvida.

\begin{abstract}
A capacidade que uma população e seus governantes têm de assimilar o conceito de que o lixo disposto de forma inadequada, sem qualquer forma de tratamento, pode ser uma séria ameaça à saúde pública, está diretamente relacionada às soluções que esta população adota como tratamento final para seu lixo. O Homem é o maior responsável por este desequilíbrio ambiental. Percebe-se hoje a importância de uma mudança de atitude na busca de garantirmos nossa própria sobrevivência. (A SITUAÇÃO..., 2004)
\end{abstract}

Falando em termos de Brasil, os índices são alarmantes, pois convive-se com a maioria do lixo produzido no país. São aproximadamente $250 \mathrm{mil}$ toneladas/dia de lixo produzidas no país. (A SITUAÇÃO..., 2004)

\title{
5. Conclusão
}

O saneamento em Criciúma passa um momento crítico, pois além de se conviver com o próprio esgoto gerado na cidade, sem coleta e tratamento adequado, também há o problema do acumulo desenfreado dos resíduos sólidos. Os órgãos públicos, responsáveis pela saúde da população, não se comprometem de forma adequada. Pensemos em uma Vigilância Sanitária pouco atuante, que não presencia essa falta de conhecimento por parte dos estabelecimentos de saúde. Fica demonstrado pelo estudo realizado que a gestão dos resíduos sólidos de serviço de saúde é crítica na cidade de Criciúma e que há um despreparo por parte da maioria dos responsáveis por cuidar dos RSSS nos estabelecimentos amostrados. Isto implica que o perigo à saúde pública oferecido por tais resíduos não está sendo minimizado conforme preconiza todos os procedimentos descritos pelas normas da ANVISA e da resolução CONAMA na área. Percebeu-se ainda que é preciso a criação de um aterro sanitário em Criciúma e maiores esclarecimentos aos estabelecimentos geradores de RSSS para que se possa construir um ambiente mais seguro e saudável do ponto de vista ambiental e de saúde pública, em uma região já tão sacrificada pelos passivos da mineração do carvão.

\section{Referências}

A SITUAÇÃO atual dos Resíduos Hospitalares no Brasil. Revista Meio Ambiente Industrial, Ano V, 30.ed., Março/Abril de 2001. Disponível em: <www.futurasgeracoes.com.br/htm/residuoshospitalares.htm> Acesso em: 02 de maio de 2005.

ANVISA. Resíduos de serviços de saúde terão regras nacionais da origem até o seu destino final.

Disponível em: http://www.anvisa.gov.br/divulga/noticias/2003/060303.htm. Acesso em: 02 de março de 2004.

Resolução RDC no 306, de 07 de dezembro de 2004. Disponível em: <www.e-

legis.bvs.br/leisref/public/showAct.php?id=13554\&word=>. Acesso em 09 de março de 2005.

Resolução RDC no 33, de 25 de fevereiro de 2003. Disponível em: http://elegis.bvs.br/leisref/public/showAct.php?id=7869. Acesso em 15 de março de 2004.

CONSELHO Nacional do Meio Ambiente - CONAMA. Resolução no 283, de 12 de Julho de 2001. Disponível em: http://www.resol.com.br/textos/RESOLUÇÃO\%20CONAMA\%20283.htm. Acesso em: 12 de março de 2004.

Resolução n5 de 5 de agosto de 1993. Disponível em: http://www.resol.com.br/textos/conama0593.htm. Acesso em: 12 de março de 2004. 
COSTA, A. M. P. Elaboração e Avaliação da Implantação de um "Modelo Básico" de Plano de Gerenciamento de Resíduos de Serviços de Saúde em Unidades Hospitalares da Região Metropolitana da Baixada Santista. São Paulo; 2001 [Dissertação de Mestrado - Faculdade de Saúde Pública da USP].

LICENCIAMENTO ambiental de sistemas de incineração de resíduos de serviços de saúde. Disponível em: http://www.sindihospa.com.br/download. Acesso em: 04 de março de 2004

LIXO hospitalar vira epidemia em aterros sanitários. O globo. Jan. 2004. Disponível em: http://www.silcon.com.br/destaques todos.php. Acesso em: 05 de março de 2004.

RISSO, W. M. Gerenciamento de resíduos de serviço de saúde: caracterização como um instrumento básico para abordagem do problema. São Paulo: 1993. [Dissertação de Mestrado - Faculdade de Saúde Pública da USP].

SHNEIDER, E. S.; RÊGO, R. C. E.; CALDART, V.; ORLANDIN, S. M. Manual de Gerenciamento de Resíduos Sólidos de Serviços de Saúde. Editora CLR Balieiro. P.173, 2001

STEVENSON, William J. Estatística Aplicada à Administração. São Paulo: Editora Harbra, 1986, p. 217 